\title{
PSO-based optimization of PI regulator and VA loading of a SRF-based multi-converter DVR
}

\author{
P. Vasudeva Naidu ${ }^{1 *}$, B. Basavaraja ${ }^{2}$ \\ ${ }^{1 *}$ Department of Electrical \& Electronics Engineering, GITAM University, INDIA \\ ${ }^{2}$ Department of Electrical \& Electronics Engineering, UBDT Engineering College (VTU), Davanagere, INDIA \\ *Corresponding Author: e-mail: vdnaidu_p3@yahoo.co.in, banakara36@gmail.com Tel+91-9440141343
}

\begin{abstract}
This paper deals with a design of optimal parameters of PI regulator in voltage control loop. The design aims to minimize voltampere (VA) loading of synchronous reference frame (SRF) based multi converter-DVR in parallel feeder distribution systems. To improve the power quality by using power conditioner with multi converters in each feeder distribution system under different load considerations, a dynamic model of synchronous-reference- frame (SRF) has been adopted. It is desirable to have optimization of PI components and generate the reference compensate voltages for series active filters (SAF) of MC-DVR. Therefore, series active filters help to inject optimal voltages at optimal angle in such a way that a minimum VA loading of MCDVR is possible. The optimal value PI components and optimal series injected angle of series active power filters are computed using particle swarm optimization (PSO) technique and the results are verified with genetic algorithm (GA). The simulation results show that the proposed PSO technique causes minimum error and minimum VA loading angle by optimally choosing parameters of PI and minimum VA angle as compared to GA technique.
\end{abstract}

Keywords: Active power filter (APF), synchronous reference frame (SRF), Genetic algorithm (GA), Particle Swarm Optimization (PSO) and multi converter dynamic voltage restorer (MC-DVR).

DOI: http://dx.doi.org/10.4314/ijest.v7i1.5

\section{Introduction}

Increased usage of electronic controllers and switched apparatus in domestic and industries, is leading to several power-quality (PQ) problems (Bollen, 2003) such as harmonics, Voltage flickers, Voltage sags, etc. Some sensitive loads require a pure A.C supply voltage for proper functioning of load necessitating a solution to the power quality problems (Ray Arnold, 2001). A few years back passive filters and active filters started being used in combination with the conventional converters to meet power quality standards (Reid, 1996). Presently, using custom power devices customers gain in terms of cost and quality of power. Custom power devices are also used for mitigating power quality issues like voltage/current unbalances, harmonics, poor power factor, sag/swells and interruptions. Broadly, custom power devices are classified as shunt active power filters, Series active power filters, and combined shunt-series active power filters (APFs) (Fujita and Akagi, 1998). Shunt active power filters are connected in a shunt arrangement with load and usually called Distribution Static Compensator (D-STATCOM) (Hague, 2001). They are used for mitigating current related power quality problems like reactive power compensation, harmonic elimination and load balancing. Series Active Power Filter (SEAPF) is connected in series with the load and is also called as Dynamic Voltage Restorer (DVR). DVR (Wang et al, 2006) is used for overcoming voltage related power quality issues like sag/swell, voltage harmonics and unbalances in voltages quantities in power distribution systems. The current research focuses on controlling the power flow of an entire line (Aredes et al, 1998) rather than a sub network or a portion of a line, to extend the DVR with the help of multi converter to control the power flow of the entire line rather than a portion of a line (Jindal et al, 2009).

This paper presents the PSO-based voltage controlled loop and minimization of volt-ampere loading of the synchronousreference-frame (SRF) (Rodríguez et al, 2007) based multi converter-DVR (MC-DVR). MC-DVR which consists of two series 
voltage source converters (VSC-1 and VSC-2) which are connected back to back with the help of common dc capacitor $\mathrm{C}_{\mathrm{dc}}$. The VSCs are 3-level (H-bridge) inverters which work independently and they work on the output feedback synchronous reference frame (SRF) based Control (Kesler and Ozdemir, 2009) with help of PI regulator. By using GA and PSO techniques optimal PI regulator components $\left(\mathrm{K}_{\mathrm{p}}\right.$ and $\left.\mathrm{K}_{\mathrm{i}}\right)$ are found which reduce the steadystate error in voltage controlled loop. After minimizing the steady state error to generate reference voltage signals and switching signals to VSC1 and VSC2 by sinusoidal PWM generator constant the dc-link voltage. Which is used to find the switching times above converters, such that their bus voltages and currents can be accurately traced as per requirement. Here feeder1 employs VSC1 in series with PCC bus-1 and feeder2 employs VSC2 in series with PCC bus-2 which are as shown in figure 1. The two VSCs are formed by the combination of reactor $\left(\mathrm{L}_{\mathrm{f}}\right)$, ac filter capacitors $\left(\mathrm{C}_{\mathrm{f}}\right)$ and three phase converters to prevent the flow of the harmonic currents into the distribution system generated due to switching at each phase of PCC. The voltages at PCC bus1 and bus2 along with load voltage are regulated by MC-DVR (Jindal et al 2008). It also regulates against voltage sags and swells and voltage harmonic content $\left(\mathrm{v}_{\mathrm{h}}\right)$ with minimum VA loading. The minimum real power injection (Yashomani et al, 2007) of the MC-DVR has also been achieved with the voltage injection by series active filter at an optimum angle with respect to source voltage. In this paper, the effects of both source voltage and the VA loading of MC-DVR are minimized by injecting a series active filter voltage at an optimum angle with respect to the sag voltage. The proposed methodology ensures that the minimum VA loading (Shady Hossam Eldeen Abdel Aleem et al, 2012) is obtained by Genetic Algorithm (GA) and Particle Swarm Optimization technique (PSO) (Saravanan et al, 2007). Which are utilized as tools for evaluating the optimum angle of voltage injection with constraints on THD of load voltages. Simulation results on a power distribution system are carried out and results are presented.

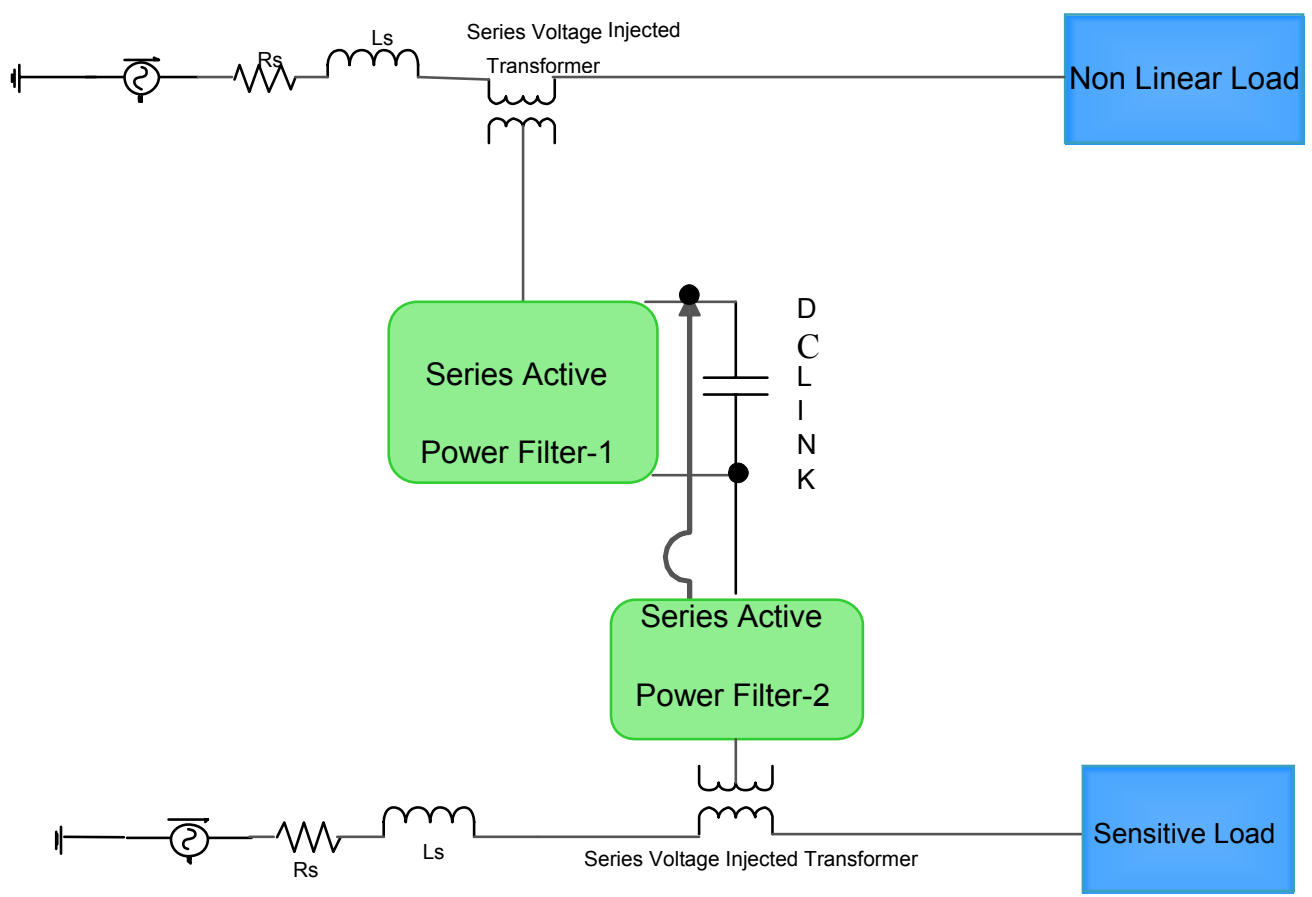

Figure 1.The single line diagram of conventional MC-DVR

\section{Modelling}

\subsection{MC-DVR dynamic model}

The considered electrical circuit is a two feeder, three-phase three-wire system. Figure 1 shows the internal connections of the MC-DVR, with VSCs, load and the power network.The VSCs are used for injection of controllable voltage $\mu_{1} \mathrm{~V}_{\mathrm{dc}}$, and $\mu_{2} \mathrm{~V}_{\mathrm{dc}}$ in order to control load voltage and PCC bus voltages under the closed loop. The de link voltage may be self-supported by a dc link capacitor for the case of MC-DVR. Figure 2 shows the single line diagram of of conventional MC-DVR compensated parallel feeder distribution system. The Filters that are connected across both the inverters are represented by $L_{s e 1} C_{s e 1}$ and $L_{s e 2} C_{s e 2}$. The switching loss of inverter and the copper losses of the connecting transformer are represented by resistance $R_{s e 1}$ and $R_{s e 2} . R_{s 1}$ and $L_{s 1}$ represent feeder1 resistance and inductance while $R_{s 2}$ and $L_{s 2}$ represent feeder2 resistance and inductance. Nonlinear load 
$i_{h}$ with $R_{l 1} L_{l 1}$ load is carried on feeder1 and sensitive load $R_{l 2} L_{l 2}$ is carried on feeder2. The $\mathrm{VSC}_{1}$ and $\mathrm{VSC}_{2}$ are supplied by common capacitor, and the voltage across each capacitor is denoted by $\mathrm{V}_{\mathrm{dc}}$.

By using the Kirchhoff laws in the above equivalent circuit, a state space model is formulated.

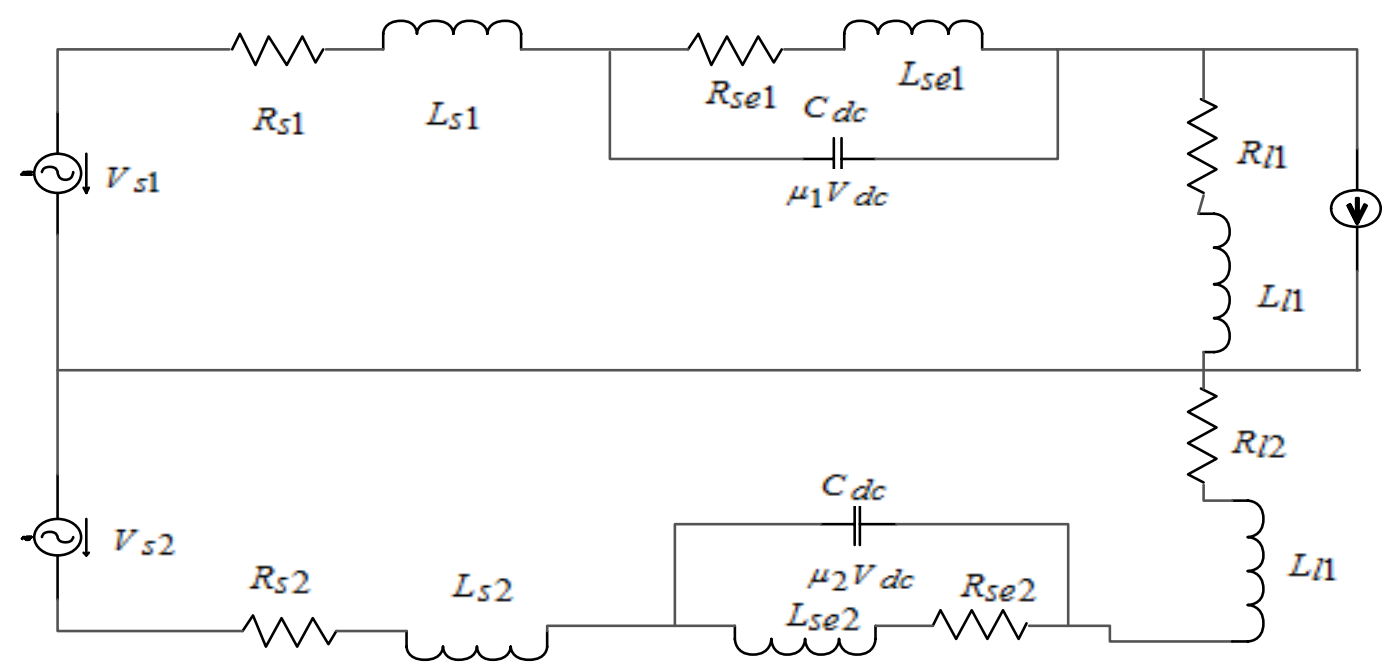

Figure 2.The single phase equivalent circuit of MC-DVR compensated parallel distribution system

$$
\begin{aligned}
& L_{s 1} \frac{d i_{1}}{d t}=-R_{s 1} i_{1}+V_{s d 1}-V_{s 1}+V_{l 1} \\
& L_{s e 1} \frac{d i_{2}}{d t}=-R_{s e 2} i_{2}-V_{s d 1}+u_{1} V_{d c} \\
& L_{l 1} \frac{d i_{4}}{d t}=-R_{l 1} i_{3}+V_{l 1} \\
& C_{s e 1} \frac{d V_{s d 1}}{d t}=i_{2}-i_{1} \\
& L_{s 2} \frac{d i_{4}}{d t}=-R_{s 2} i_{4}+V_{s d 2}-V_{s 2}-R_{l 2} i_{4} \\
& L_{s e 2} \frac{d i_{5}}{d t}=-R_{s e 2} i_{5}-V_{s d 2}+u_{2} V_{d c} \\
& C_{s e 2} \frac{d V_{s d 2}}{d t}=i_{5}-i_{1}
\end{aligned}
$$

Where $\mu_{1}$ and $\mu_{2}$ represent the duty ratio of the control variables of series and shunt VSCs.

\section{Switching Control}

\subsection{Switching Control of Series Active Power Filter (SAPF):}

The proposed SAPF control strategy (Hamid et al, 2009) is mainly aimed at controlled voltage source and generates mainly to obtain constant load terminal voltage at the desired point at a required level. The difference of the supply voltage and the ideal load voltage is compensated by injecting voltage by the series APF. These injected voltages cancel out the distortions in supply voltages. Figure 3 shows series APF block diagram. The synchronous reference (dq0) frame consists of detected source voltage.

$$
v_{s_{-} d q o}=T_{a b c}^{d q o} v_{s_{-} a b c}
$$


The instantaneous source voltages include oscillating components $\left(\tilde{v}_{s_{-} d}\right.$ and $\left.\tilde{v}_{s_{-} \mathrm{q}}\right)$, average components $\left(\bar{v}_{s_{-} d}\right.$ and $\left.\bar{v}_{s_{-} \mathrm{q}}\right)$ and under-unbalanced source voltage with harmonics. Oscillating components $\left(\tilde{v}_{s_{-} d}\right.$ and $\left.\tilde{v}_{s_{-} \mathrm{q}}\right)$ have source voltage negative-sequence components and they will have harmonics as well, under distorted load conditions. So, constant source voltage can be achieved by cancelling the $\tilde{v}_{s_{-} \mathrm{q}}=0$ through the objective SAPF, even under unbalanced conditions. Therefore, the expected load voltage in the synchronous dqo reference frame $\left(v_{l_{-} a b c}^{\exp }\right)$ assumes to be constant.

$$
v_{l_{-} d q o}^{\exp }=T_{a b c}^{d q o} v_{l_{-} a b c}^{\exp }
$$

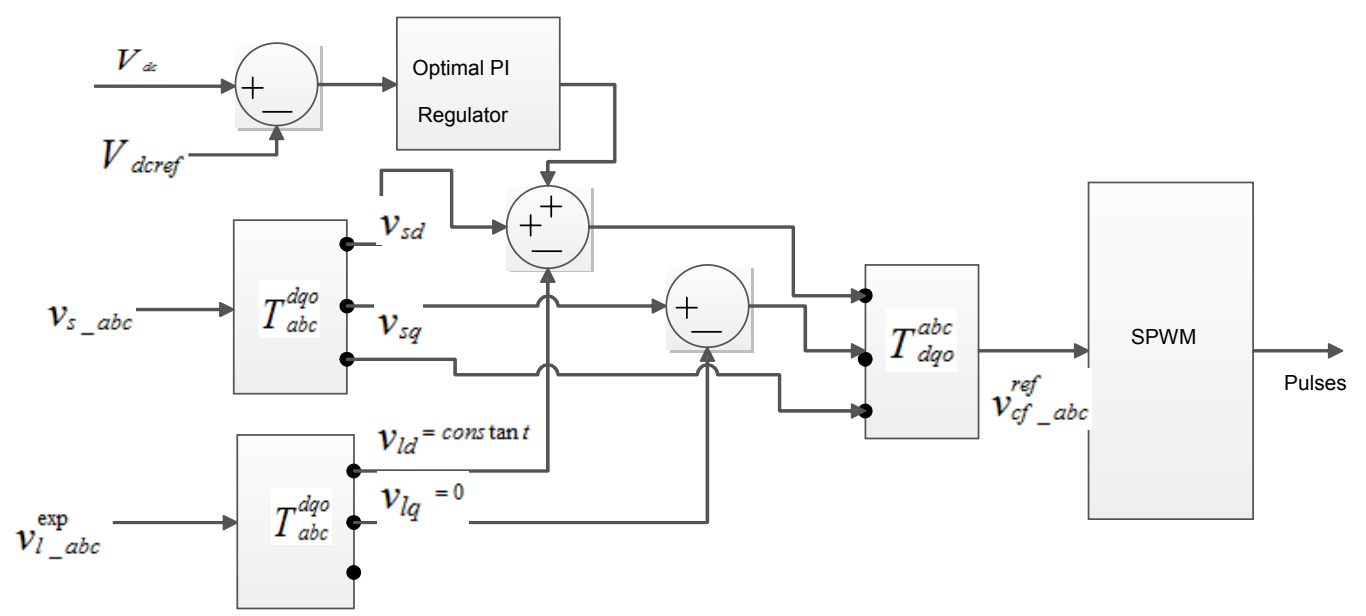

Figure 3. SRF Based Controlled Series Active Power Filter

Here the $a b c$ reference frame $\left(v_{l_{-} d q o}^{\exp }\right)$ represents assumed load voltages and synchronous dqo reference frame represents compensating reference voltage $\left(v_{\mathrm{cf}_{-} d q o}^{r e f}\right)$ and is given by

$$
v_{\mathrm{cf} \_d q o}^{r e f}=v_{s_{-} d q o}-v_{l_{-} d q o}^{\exp }
$$

By using SPWM voltage control technique dqo compensating reference voltage is then transformed back into the $a b c$ reference frame.

\section{Design of PI Regulator by using GA and PSO}

The fundamental equations that govern the design of PI regulator are presented as follows in equations (8) to (10). The SAF controls the injected voltage with the help of the duty cycle of the PWM converter (Vadirajacharya et al, 2011). The main problem of voltage control is to determine the duty cycle in such a way that the dc-link voltage remains constant and to produce suitable injected voltage to cancel the load voltage problems. The main objective of controlling the injected voltage is accomplishing the precise compensation of the harmonic component. Hence, the actual load voltage and estimated reference voltages in a SPWM controller are indirectly controlled through this processing. These reference voltages are estimated by regulating dc-link voltages. In order to estimate the steady-state error in the dc-link voltages a PI controller is used. A mathematical model is required for the stability analysis and, hence, for determining the parameters of the PI controller. The block diagram of the voltage controller loop is shown in Figure 4, where G is gain of the PI controller; $\mathrm{Kc}(\mathrm{s})$ is transfer function of the PWM converter. In order to derive the linear model of PWM converter, a small-signal perturbation technique is applied to obtain its corresponding transfer function. In this method, the system is assumed to be in steady state operation and the equations linearized even for small perturbation. Equating the rate of change of associated energy, describes the relation between the ac side and dc-link side quantities of the PWM converter. 
The average rate at which energy being absorbed by the DC-Link capacitor is

$$
p_{D C-\text { Link }}=\frac{d\left(\frac{1}{2} C_{d c} V_{d c}^{2}\right)}{d t}
$$

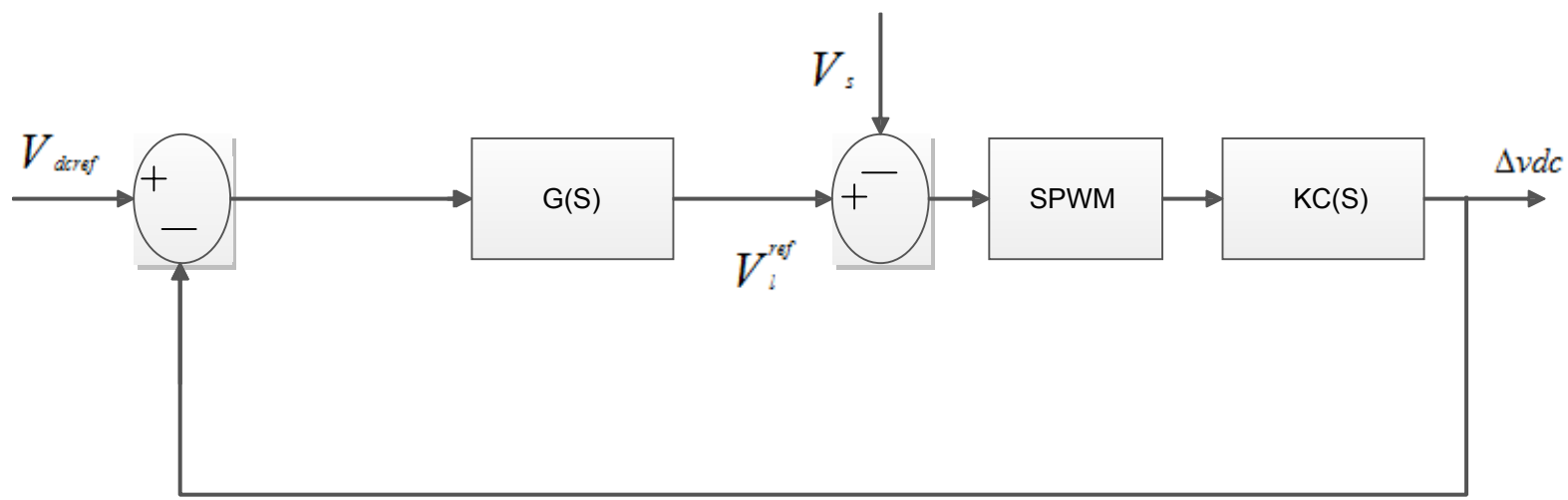

Figure 4. Voltage control loop

The power input to the PWM converter

$$
p_{\text {Conveter }}=3\left(v_{\text {inj }} I_{\text {se }}\right)
$$

The average rate of change of energy associated with the capacitor filter $\left(C_{s e}\right)$

$$
p_{\text {Filter }}=3\left(\frac{d\left(\frac{1}{2} C_{s e} v_{i n j}^{2}\right)}{d t}\right)
$$

Ohmic loss in the resistor $\left(R_{\text {se }}\right)$

$$
p_{\text {loss }}=3\left(\frac{v_{i n j}^{2}}{R_{s e}}\right)
$$

Equating the average rate of change of the change of energy

$$
p_{D C-\text { Link }}=p_{\text {Conveter }}-p_{\text {Filter }}-p_{\text {loss }}
$$

In order to linearize the power equation, when a small perturbation is applied in the input voltage of converter about a steady-state operating point, the average dc-link voltage $\}$ will also get perturbed by a small amount around its steady-state operating point hence, by substituting (15)

$$
\begin{aligned}
& v_{i n j}=v_{i n j o}+\Delta v_{i n j} \\
& V_{d c}=V_{d c o}+\Delta V_{d c} \\
& C_{d c} V_{d c o} \frac{d V_{d c}}{d t}=\left(v_{i n j o} I_{s e}+\Delta v_{i n j} I_{s e}-C_{s e} v_{i n j} \frac{d\left(\Delta v_{i n j}\right)}{d t}-\frac{v_{i n j o}^{2}}{R_{s e}}-2 v_{i n j o} \Delta v_{i n j}\right)
\end{aligned}
$$


At steady-state operating point $\quad \Delta V_{d c}=0 ; \Delta v_{i n j}=0$

Therefore Equ (17) will be modified to

$$
0=\left(v_{i n j o} I_{s e}-\frac{v_{\text {injo }}^{2}}{R_{s e}}\right)
$$

The relationship between $\Delta V_{d c}$ and $\Delta v_{i n j}$ can be obtained by subtracting (18) and (17)

$C_{d c} V_{d c o} \frac{d V_{d c}}{d t}=\left(\Delta v_{i n j} I_{s e}-C_{s e} v_{i n j} \frac{d\left(\Delta v_{i n j}\right)}{d t}-\frac{2 v_{i n j o} \Delta v_{i n j}}{R_{s e}}\right)$

Sinusoidal PWM Converter transfer function $K_{c}(s)$ for operating point can be obtained from

$$
K_{c}(s)=\frac{\Delta V_{d c}}{\Delta v_{i n j}}=3\left(\frac{\left(I_{s e}-C_{s e} v_{i n j} s-\frac{2 v_{i n j o}}{R_{s e}}\right)}{C_{d c} V_{d c o} s}\right)
$$

The characteristic equation of the voltage control loop is used to obtain the of PI regulator, which can be written as

$$
1+\left(K_{p}+\frac{K_{i}}{s}\right) K_{c}(s)=0
$$

This characteristic equation is used to determine the components of the PI regulator. The analysis of this characteristic equation determines the response and defines the damping factor of the voltage control loop, by substituting the values shown in table 1.

\subsection{PI regulator components by using Ziegler's \& Nichols's method:}

Using Routh-Harwitz criteria for system stability, the limit of the stability region is found out for the characteristic equation shown in (21). The parameters of the PI regulator by using trial and error method $K_{p}$ and $K_{i}$ are obtained as 0.1 to 0.5 and 10 . For the selected values of $K_{p}$ and $K_{i}$ in the stable region, the transient response of the voltage control loop for the step change is plotted as shown in figure 5 .

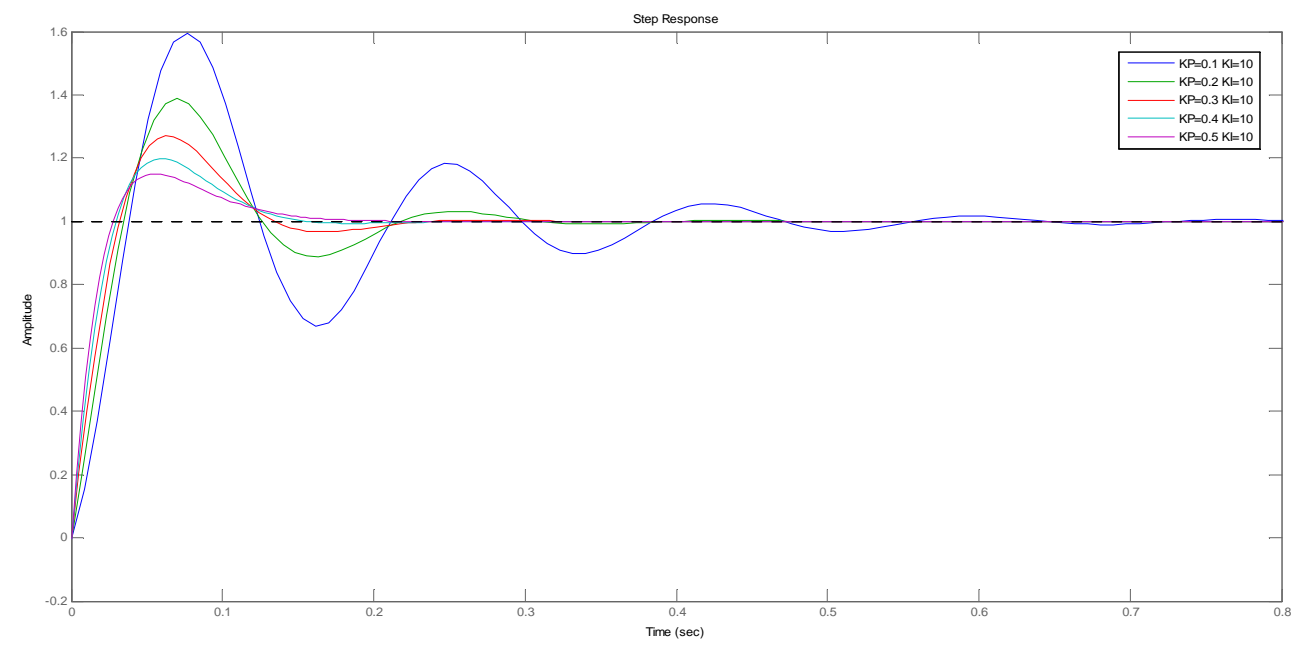

Figure 5. The characteristics of the step response for the selected values of $k_{p}$ and $k_{i}$ by using Ziegler's \& Nichols's 
Now to find the optimum value of $\mathrm{K}_{\mathrm{p}}$ and $\mathrm{K}_{\mathrm{i}}$ in most stable regions, the following optimization methods are used:

\subsection{Optimization of PI regulator components by using genetic algorithm}

GA has been used for global optimization of the parameters of control system, which are complex and difficult to solve using Ziegler's \& Nichols's method, and conventional optimization methods. GA maintains a set of solutions called population and repeatedly modifies them. At each step, the GA selects individuals from the current population to be parents and uses them to produce the children for the next generation called Reproduction. Candidate solutions are usually represented as strings of fixed length, called chromosomes. A fitness or objective function is used to reflect the best of each member of the population. Given a random initial population, GA operates in cycles called generations, as follows:

1. Each member of the population is evaluated using a fitness function.

2. The population undergoes reproduction in a number of iterations. One or more parents are chosen stochastically, but strings with higher fitness values have a higher probability of contributing an offspring.

3. Genetic operators such as crossover and mutation are applied to parents to produce offspring.

4. The offspring is inserted into the population, and the process is repeated.

Table 1.Parameters of GA and PSO

\begin{tabular}{|c|c|}
\hline Parameters & Values \\
\hline Population /Swarm size: & 100 \\
\hline No of Iteration: & 50 \\
\hline C1 and C2 & 1 and 1.4 \\
\hline Weighting factor (w) & 0.9 \\
\hline
\end{tabular}

The parameters of genetic algorithm are shown in table 1. Now the Characteristic equation (22) is optimized by using genetic algorithm and the optimal values of controller parameters $k_{p}$ and $k_{i}$ in the most stable region for the step response of the voltage control loop. The response of characteristics equation shown in figure 6 and the characteristics of the step response for the optimal values of $\mathrm{k}_{\mathrm{p}}$ and $\mathrm{k}_{\mathrm{i}}$ are tabulated in table 3 .

\subsection{Optimization of PI regulator components by using particle swarm optimization:}

The PSO is best suited for optimizing non-smooth and non-linear functions as compared to evolutionary methods like genetic algorithms, Newton-based method etc (Panda. S et al, 2008). They also have the advantage of not being stuck to local minimum. In this work the PSO was considered for optimizing characteristic equation and to determine the components of the PI regulator. The PSO is a population-based optimization technique that is originally inspired by the sociological behaviour associated with bird flocking and fish schooling. It is used to find a solution to an optimization problem in a search space and predict behaviour of all particles in the presence of various constraints and objectives.

For each iteration of the particle during the execution of the algorithm, the velocity of each particle is modified using its current velocity and its distance from personal best position "pbest" and global best position "gbest" according to

$$
v_{i}^{n+1}=w(n) * v_{i}^{n}+c_{1}^{*} \operatorname{rand} 1() *\left(\text { pbest }_{i}^{n}-x_{i}^{n}\right)+c_{2} * \operatorname{rand} 2() *\left(\text { gbest }_{i}^{n}-x_{i}^{n}\right)
$$

The first term represents the particle's current velocity; the second term represents the cognitive part of velocity, while the third term represents the social interactive part of the velocity.

After the velocity update is done, each particle moves to its new position according to

$$
x_{i}^{n+1}=x_{i}^{n}+v_{i}^{n+1}
$$

Considering minimization problems, then the personal best position at the next time step $n+1$, is calculated as

$$
\text { pbest }_{i}^{n}=\text { pbest }_{i}^{n} ; \quad \text { If } f\left(x_{i}^{n+1}\right)>\text { pbest }_{i}^{n}
$$




$$
\text { pbest }_{i}^{n}=x_{i}^{n+1} \quad ; \quad \text { If } \quad f\left(x_{i}^{n+1}\right) \leq \text { pbest }_{i}^{n}
$$

The global best gbest $_{i}^{n}$ position at time step is calculated as

$$
\operatorname{gbest}_{i}^{n}=\min \left(\text { pbest }_{i}^{n}\right)
$$

Therefore it is important to note that the personal best $p b e s t_{i}^{n}$ is the best position that the individual particle has visited since the first step. On the other hand, the global best $g$ best ${ }_{i}^{n}$ position is the best position discovered by any of the particles in the entire swarm.

The parameters of particle swarm optimization are shown in table 2. Now the Characteristic equation (22) is optimized by using PSO and the optimal values of controller parameters $\mathrm{k}_{\mathrm{p}}$ and $\mathrm{k}_{\mathrm{i}}$ in the most stable region for the step response of the voltage control loop. The response of characteristics equation shown in figure 6 and the characteristics of the step response for the optimal values of $\mathrm{k}_{\mathrm{p}}$ and $\mathrm{k}_{\mathrm{i}}$ are tabulated in table 2 .
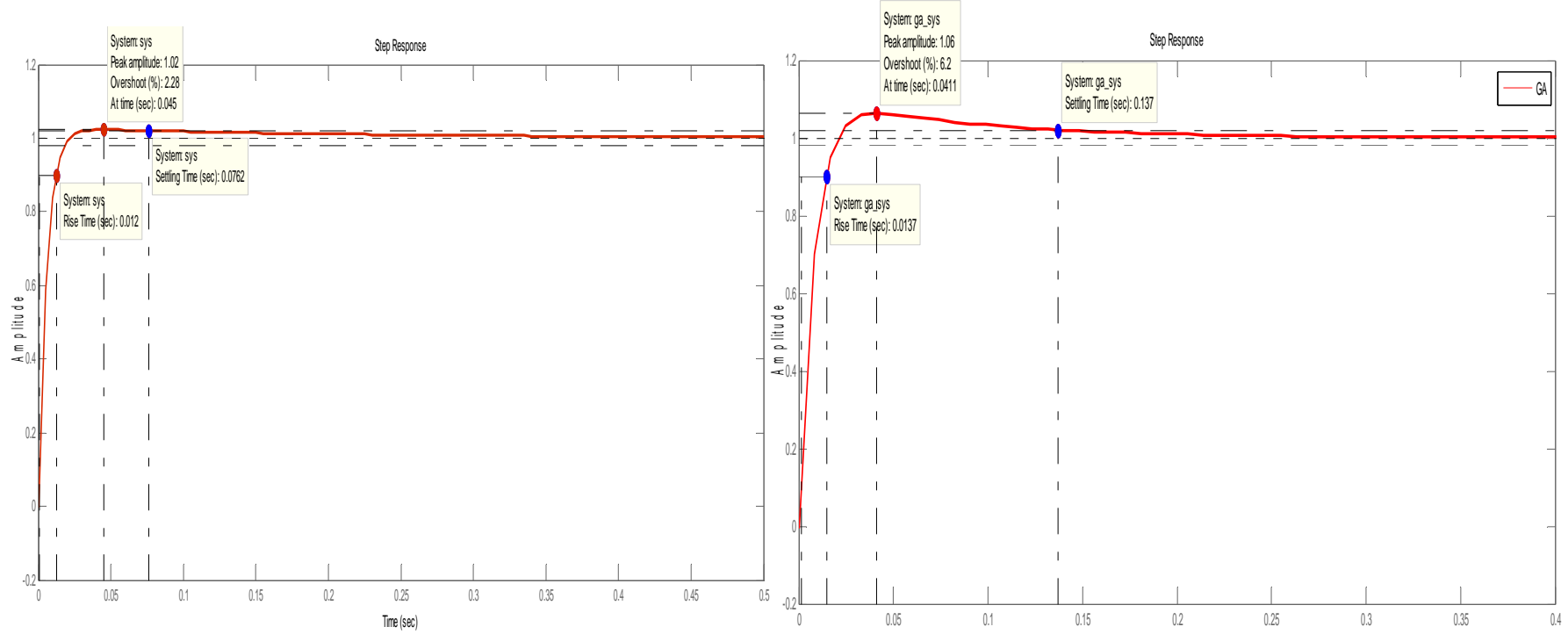

Figure 6. The characteristics of the step response for the optimal values of $\mathrm{k}_{\mathrm{p}}$ and $\mathrm{k}_{\mathrm{i}}$ by using PSO and GA

Table 2. Comparison of parameters \& Specifications

\begin{tabular}{|c|c|c|}
\hline Parameters & With GA & With PSO \\
\hline $\mathrm{Kp}$ & 0.9938 & 1.1925 \\
\hline $\mathrm{Ki}$ & 11.5855 & 12.9559 \\
\hline For above optimal Kp and Ki values step response characteristics \\
\hline Rise time & 0.0137 & 0.012 \\
\hline Percentage over shoot & 6.2 & 2.28 \\
\hline Settling time & 0.137 & 0.0762 \\
\hline Error & 1.4776 & 1.0354 \\
\hline
\end{tabular}




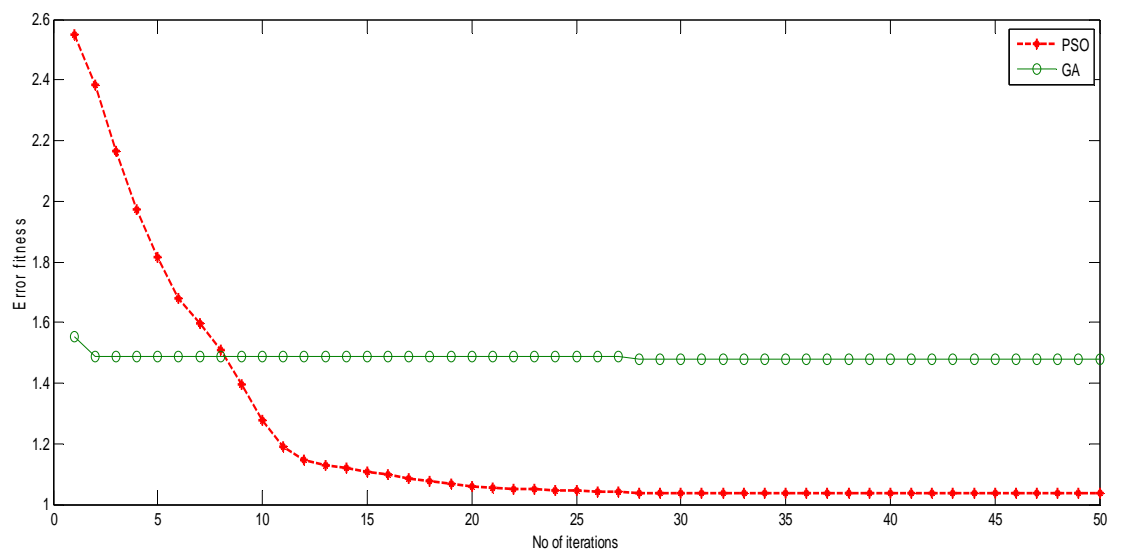

Figure 7.Error fitness value by using GA \& PSO

In the system above, response error is minimized more by the particle swarm optimization than by the genetic algorithm shown in figure 7.

\section{Minimization of VA Loading by using Optimization Techniques}

Figure 8 shows the phasor diagram of MC-DVR with voltage sag. Source voltages are $\mathrm{V}_{\mathrm{s} 1}$ and $\mathrm{V}_{\mathrm{s} 2}$, the load voltages are $\mathrm{V}_{\mathrm{L} 1}$ and $\mathrm{V}_{\mathrm{L} 1}$ and load currents in both feeders are $\mathrm{I}_{\mathrm{L} 1}$ and $\mathrm{I}_{\mathrm{L} 2}$ respectively. The load angle $\Phi_{\mathrm{L} 1}$ and $\Phi_{\mathrm{L} 2}$ correspond to per unit sags and $\mathrm{k}_{1}$ and $\mathrm{k}_{2}$ are magnitudes of voltage sags to be compensated at feeders1 and 2, considering the MC-DVR to be ideal. Therefore, the input active current at Feeder I can be expressed by:

$$
\begin{array}{r}
P_{s 1}=V_{s 1} I_{s 1}=V_{L 1}\left(1-k_{1}\right) I_{s 1} \\
P_{L 1}=V_{L 1} I_{L 1} \cos \phi_{L 1} \\
P_{L 1}=P_{s 1} \\
I_{s 1}=\frac{I_{L 1}}{\left(1-k_{1}\right)} \cos \phi_{L 1}
\end{array}
$$

The feeder1 active power demand is calculated as

$$
V_{s 1} I_{s 1}=V_{L 1}\left(1-k_{1}\right) I_{s 1}
$$

Where $I_{59}$ is source current in feederl and given by

$$
I_{s 1}=\frac{V_{L 1} I_{L 1} \cos \phi_{L 1}+V_{L 2} I_{L 2} \cos \phi_{L 2}}{V_{L 1}\left(1-k_{1}\right)}
$$

The expression for Voltage injected by the series VSC in feeder1

$$
\begin{array}{r}
v_{i n j}^{1}=\sqrt{\left(\left(V_{L 1} \cos \theta_{L 1}-v_{s 1}^{1}\right)^{2}+\left(V_{L 1} \sin \theta_{L 1}\right)^{2}\right)} \\
\therefore v_{i n j}^{1}=\left(1-k_{1}\right) V_{L 1} \tan \alpha \\
\tan \alpha=\left(\frac{V_{L 1} \sin \theta_{L 1}}{\left(V_{L 1} \cos \theta_{L 1}-v_{s 1}^{1}\right)}\right)
\end{array}
$$




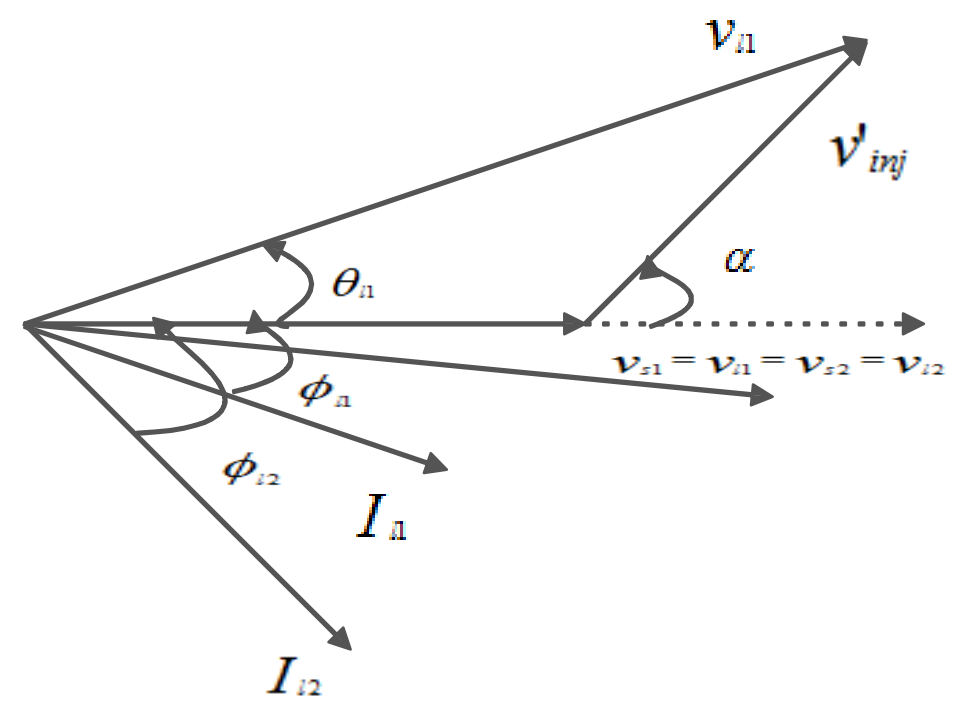

Figure 8. Phasor diagram of the MC-DVR with voltage sag.

$$
\therefore v_{i n j}^{1}=\left(1-k_{1}\right) V_{L 1} \tan \alpha
$$

Hence series VSC power rating is

$$
S_{s e 1}=\left(1-k_{1}\right) V_{L 1} \tan \alpha\left(\frac{V_{L 1} I_{L 1} \cos \phi_{L 1}+V_{L 2} I_{L 2} \cos \phi_{L 2}}{V_{L 1}\left(1-k_{1}\right)}\right)
$$

Hence power rating of the series VSC in feeder2 can be obtained, by almost equating feeder2 injected voltage to the $k_{2} V_{L 2}$ (where $k_{2}=1$ ). Therefore the expression for series -VSC power rating in feeder2 is

$$
S_{s e 2}=V_{L 2} I_{s 2}
$$

By adding equ (29) and (30), the total VA rating of overall MC-DVR can be obtained.

$$
S_{M C-D C R}=S_{s e 1}+S_{s e 2}
$$

The total VA loading of MC-DVR (G. Siva Kumar, 2012) is then the function of $k_{1}, k_{2}, \phi_{L 1}, \phi_{L 2}, \theta_{L 1}$, total harmonic distortions $T H D_{V_{-} L 1}$, load currents $I_{L 1}, I_{L 2}$ and rated fundamental voltage $V_{L 1}, V_{L 2}$. In this function except $\theta_{L 1}$, all the remaining variables are system dependents. Therefore, the function value i.e., total VA loading of MC-DVR is controlled by varying $\theta_{L 1}$. This can be expressed as a standard optimization problem as given below

$$
f\left(\theta_{L 1}\right)=S_{M C-D C R} \quad \text { Where } \theta_{L 1} \text { is }-90^{\circ}<\theta_{L 1}<90^{\circ}
$$

$\theta_{L 1}$ is the control variable with respect to which $f\left(\theta_{L 1}\right)$ has to be minimized by using GA and PSO.

\section{Results}

In the proposed analysis, SRF based MC-DVR extensive case study using simulation in sim power system toolbox of MATLAB is done as shown figure. 9 and simulation results in parallel distribution power system related to performance of the proposed SRFBased MC-DVR system as shown. The table 3 shows parameters used in the proposed analysis 
Table 3. System parameters

\begin{tabular}{|c|c|}
\hline System Parameters & Values \\
\hline System frequency $(f)$ & $50 \mathrm{HZ}$ \\
\hline Rated voltage & $380 \mathrm{~V}(\mathrm{rms}$, Phase-Phase) \\
\hline $\mathrm{R}_{\mathrm{s} 1}$ andL $\mathrm{s}_{\mathrm{s} 1}$ & $0.6 \Omega$ and $0.1 \mathrm{mH}$ \\
\hline $\mathrm{R}_{\mathrm{s} 2}$ andL $\mathrm{s} 2$ & $0.6 \Omega$ and $0.1 \mathrm{mH}$ \\
\hline Nonlinear Load & $\begin{array}{c}\text { An Universal bridge consisting of resistor } \\
(10) \Omega \text { and R-L Load }(10 \Omega \text { and } 3 \mathrm{mH})\end{array}$ \\
\hline Linear Load-1 & A three-phase resistive Load $(10) \Omega$ \\
\hline Linear Load-2 & A three-phase R-L Load (10 $\Omega$ and $10 \mathrm{mH})$ \\
\hline $\begin{array}{c}\text { VSC-1 and VSC-2 Series } \\
\left.\text { T/F ( } \mathrm{T}_{1} \text { andT } 2\right)\end{array}$ & $4 \mathrm{kva}, 200 / 180,50 \mathrm{~Hz}, 10 \%$ leakage reactance \\
\hline $\begin{array}{c}\text { Power losses in VSC- } \\
1, \mathrm{VSC}-2,\end{array}$ & $\mathrm{R}_{\mathrm{f} 1}=0.1 \Omega, \mathrm{R}_{\mathrm{f} 2}=0.1$ \\
\hline Filter capacitors & \\
\hline DC Capacitor $\left(\mathrm{C}_{\mathrm{DC}}\right)$ & $\mathrm{C}_{\mathrm{f} 1}=10 \mu \mathrm{F}$ and $\mathrm{C}_{\mathrm{f} 2}=10 \mu \mathrm{F}$ \\
\hline
\end{tabular}

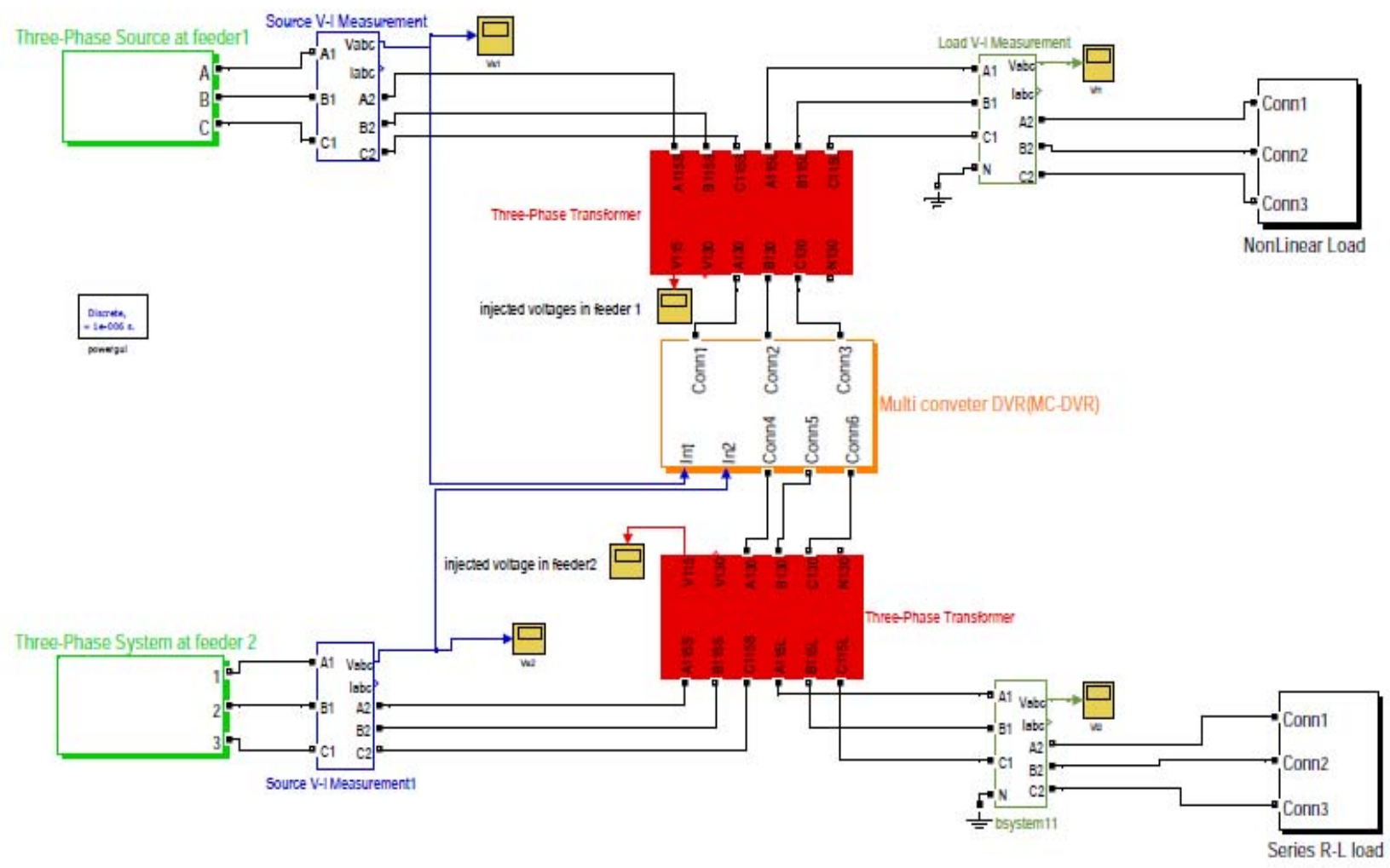

Figure 9. Simulink model of multi converter DVR (MC-DVR) in parallel feeder distribution system

A three-phase feeder 1 distribution system has a single phase voltage source designed $v_{1}(t)$ with different magnitudes $\left(v_{m 1}\right.$ and $\left.v_{m 2}\right)$ and has $5^{\text {th }}$ order harmonics.

$$
v_{1}(t)=\left(v_{m 1} \sin (\omega t)+\frac{v_{m 2} \sin (5 \omega t)}{5}\right)
$$


A three-phase feeder 2 distribution system has a single phase voltage source designed $v_{2}(t)$ with different magnitudes $\left(v_{m 1}\right.$ and $\left.v_{m 2}\right)$ and has $7^{\text {th }}$ order harmonics.

$$
v_{2}(t)=\left(v_{m 1} \sin (\omega t)+\frac{v_{m 2} \sin (7 \omega t)}{7}\right)
$$

\subsection{Voltage sag on both feeders}

In this case it is assumed that $33 \%$ voltage sag occurs on feeder1 \& 2 between intervals of time at $0.1 \mathrm{sec}<\mathrm{t}<0.2 \mathrm{sec}$ and at $0.15 \mathrm{sec}<\mathrm{t}<0.25 \mathrm{sec}$ and it is assumed that $10 \%$ voltage swell occurs on feeder 2 between intervals of time at $0.25 \mathrm{sec}<\mathrm{t}<0.3 \mathrm{sec}$, which distorts the load voltages and source voltages in each feeder. Hence we need to regulate the load voltages on both feeders with the help of SRF based MC-DVR controller with optimal PI regulator components. The MC-DVR controller injects the compensated voltage in each feeder to improve load voltages with constant DC-link voltage, as is shown in figure 10 and 11.

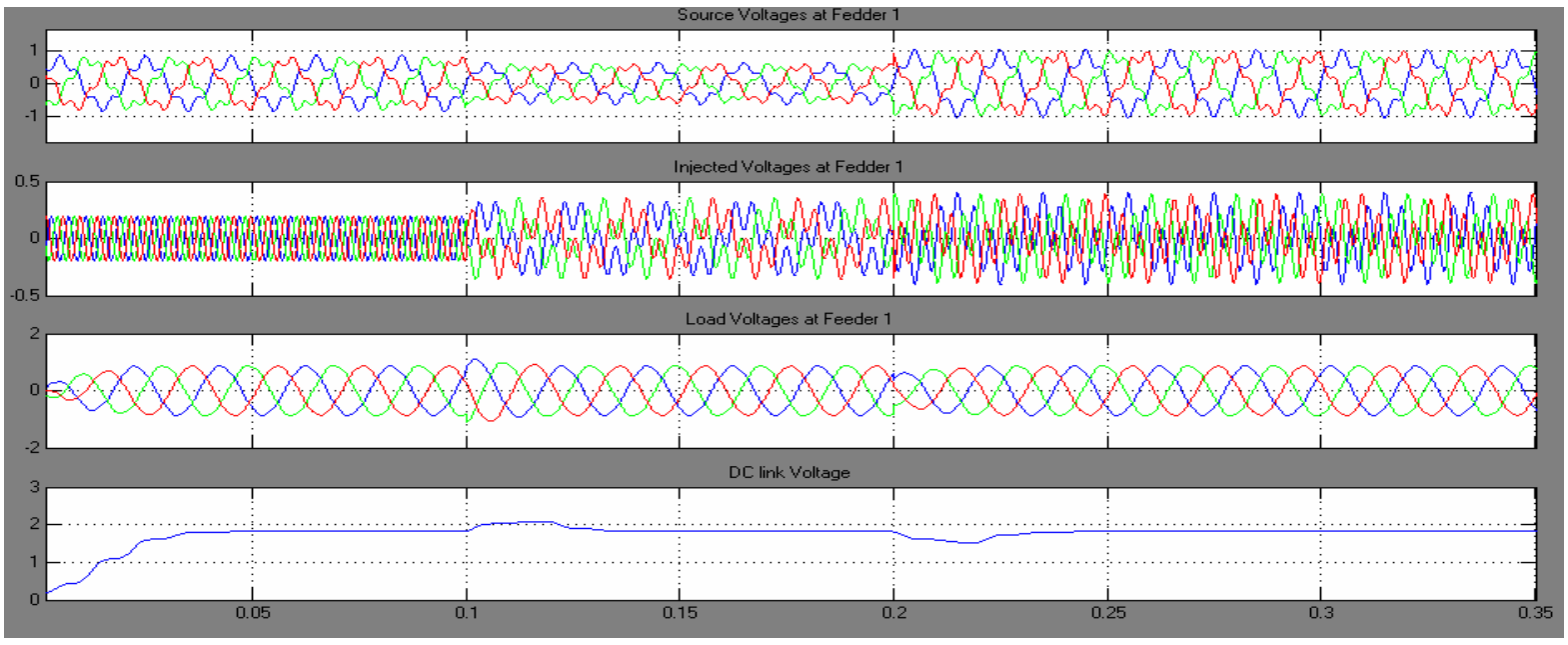

Figure 10. The source voltage, injected voltage, load Voltages and DC Capacitor Voltage $\left(\mathrm{V}_{\mathrm{DC}}\right)$ at feeder 1

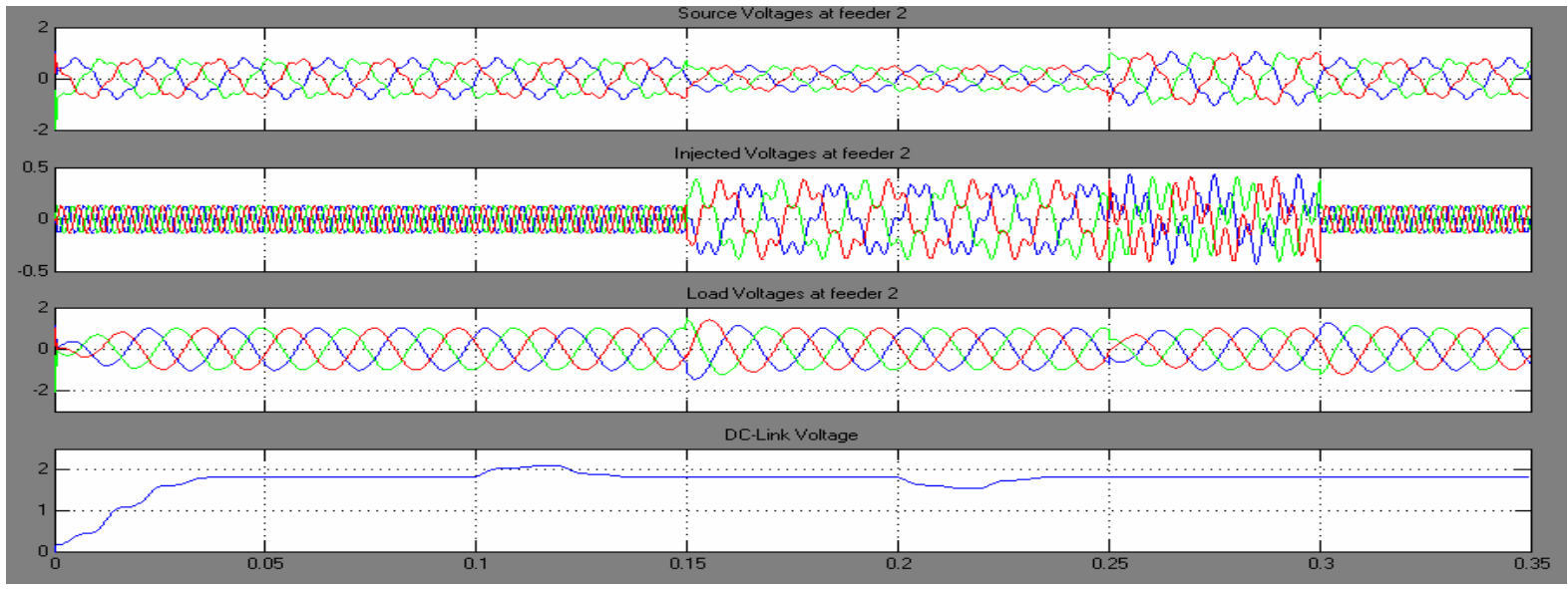

Figure 11. The source voltage, injected voltage, load Voltages and DC Capacitor Voltage $\left(\mathrm{V}_{\mathrm{DC}}\right)$ at feeder 2

\subsection{Three phase fault (LLLG) occurs in feeder2}

In this case it is assumed that the three phase fault (LLLG) occurs at feeder 2 in interval of time at $0.3 \mathrm{sec}<\mathrm{t}<0.4 \mathrm{sec}$ then healthy feeder1 inject the active power to fault feeder2 through the DC link. Hence the Series VSC 2 injected compensation voltage, and finally regulates the load L2 voltage as shown in figure 12 . 


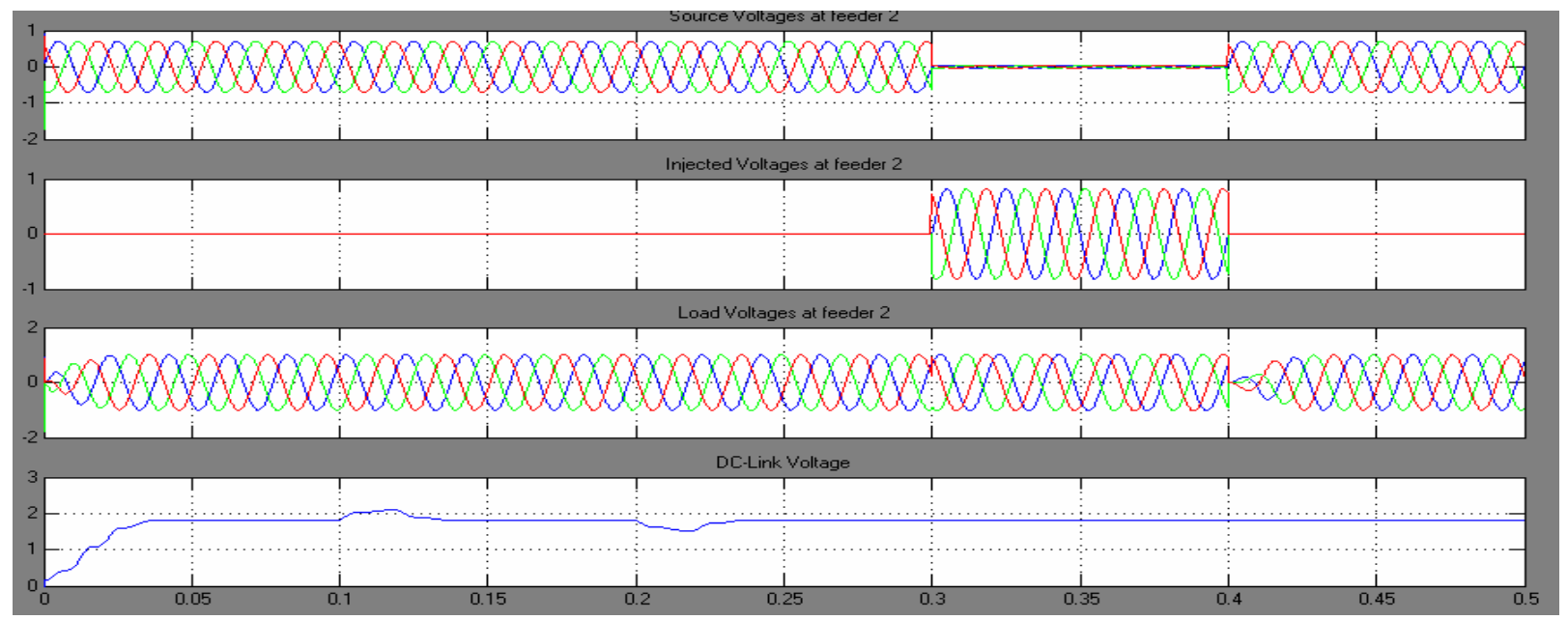

Figure 12. The phase bus voltage, injected voltage, load Voltages and DC Capacitor Voltage $\left(\mathrm{V}_{\mathrm{DC}}\right)$ at feeder 2

\subsection{Sudden load changes occur at feeder 1}

In this case it is assumed that sudden load changes occur at feeder 1 in the interval $0.3 \mathrm{~s}<\mathrm{t}<0.4 \mathrm{~s}$ which has $5^{\text {th }}$ order harmonic content of $35.04 \%$. In feeder1 DC link voltage decrease due to sudden load change now the Series VSC 1 injects compensated voltage which restores the DC-link voltage to normal value. The analysis are shown in figure 13.

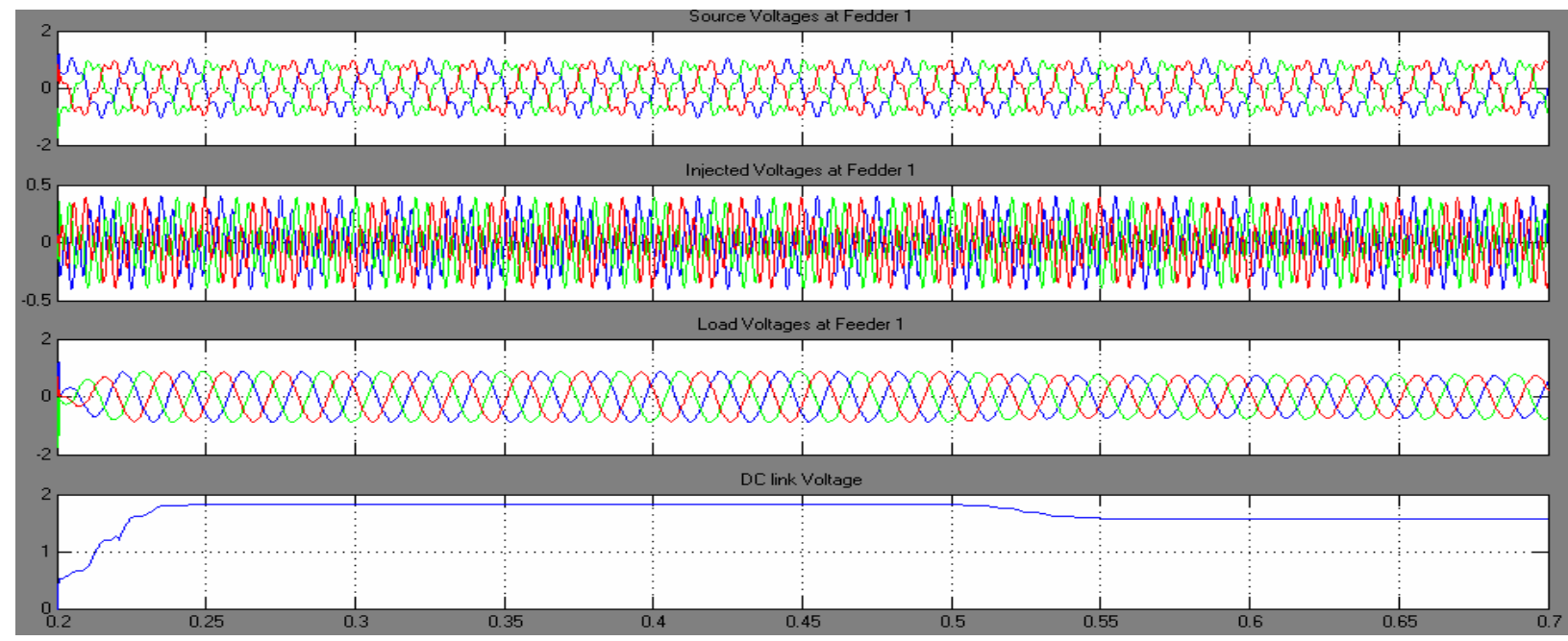

Figure. 12. The phase bus voltage, injected voltage, load Voltages and DC Capacitor Voltage $\left(\mathrm{V}_{\mathrm{DC}}\right)$ at feeder 1

By implementing proposed methodology of SRF-MC-DVR the above analysis shows that the $T H D_{V_{-} L 1}$ is brought down from $35.04 \%$ to $5 \%$ at feeder 1 and the $T H D_{V_{-} L 2}$ is brought down from $31.2 \%$ to $7 \%$ at feeder2, which within the permissible limits.

\section{4 minimization of VA Loading by using GA and PSO}

To minimize the VA loading optimum angle $\left(\theta_{L 1}\right)$ for voltage injection is found by implementing GA and PSO techniques which results in minimum total VA loading. The optimum angle $\theta_{L 1}, v_{i n j}$ and phase jump angle $\alpha$ angle can be calculated using equation (32). It is assumed that voltage sag occurs at only feederl, the per unit value of sag $k_{1}$ where $k_{1}$ is 0.6 with the given system parameters the total VA loading of MC-DVR is expressed as a function of $\theta_{L 1}$ are shown in equation (32). Using the GA and PSO technique, the above function shown in equation (32) is optimized with $\theta_{L 1}$ as the variable. The minimum VA loading 
of MC-DVR is obtained which is shown in table. 4 and analysis in figure 14(a) and 14(b), shows the global best (VA Loading) value and variation of fitness function with respect to numbers of iterations.

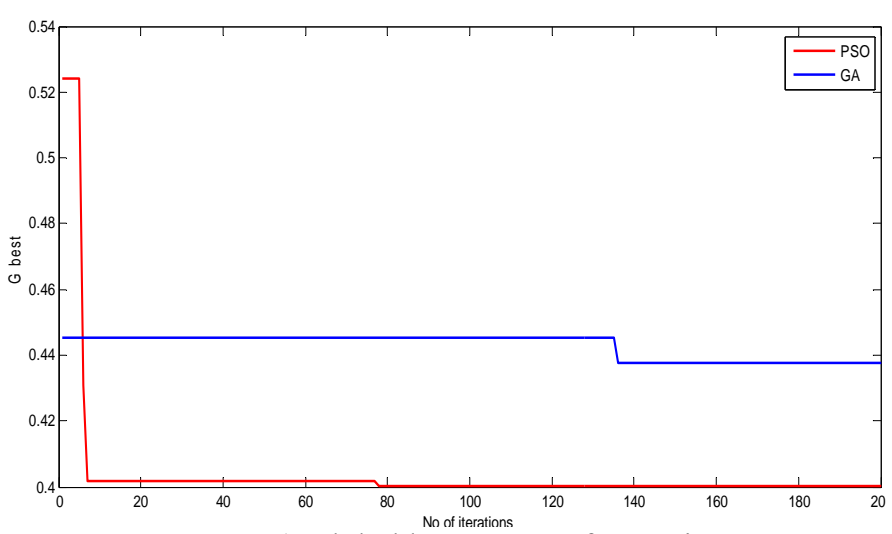

Figure 14(a) Global best vs No.of. Iterations

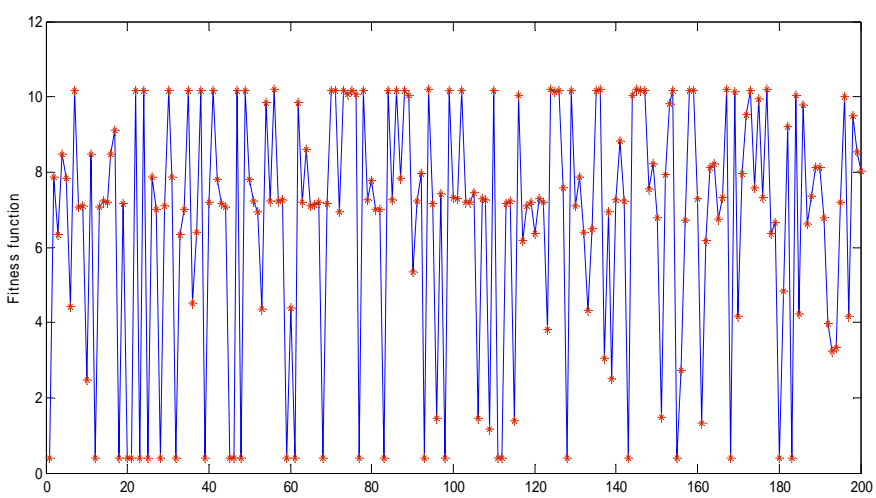

Figure 14(b) fitness function vs No.of. Iterations

Table 4. Optimization inject angle and VA loading

\begin{tabular}{|c|c|c|c|c|}
\hline $\begin{array}{c}\text { Minimization } \\
\text { function } \\
f\left(\theta_{L 1}\right)\end{array}$ & $\begin{array}{c}\text { VA } \\
\text { Loading } \\
\text { (P.U) }\end{array}$ & $\begin{array}{c}\theta_{L 1} \\
(\text { degree })\end{array}$ & $\begin{array}{c}v_{i n j} \\
(\mathrm{P} . \mathrm{U})\end{array}$ & $\begin{array}{c}\text { Angle of } \\
\text { injection } \\
\alpha \text { (degree) }\end{array}$ \\
\hline By using PSO & 0.4001 & 8.68 & 0.151 & 20.68 \\
\hline By using GA & 0.4378 & 2.36 & 0.2029 & 26.89 \\
\hline
\end{tabular}

Minimization of VA loading and minimum phase jump angle of the MC-DVR are obtained more by using the PSO than by using GA.

\section{Conclusions}

This paper has discussed design of optimized PI regulator components $\left(\mathrm{K}_{\mathrm{p}}\right.$ and $\left.\mathrm{K}_{\mathrm{I}}\right)$ and minimizing the steady state error of the voltage control loop in synchronous-reference- frame (SRF) based MC-DVR controller in three phase systems by using optimization techniques. The proposed controller improves the load voltage in adjacent parallel feeders. From the simulation carried out as described above the following conclusions can be drawn:

- The proposed MC-DVR mitigates the voltage sag from $30 \%$ to $0.5 \%$ and $5^{\text {th }}$ harmonic distortion is brought down from $35.04 \%$ to $5 \%$ at feeder 1 and regulates the load voltages in feeder 1 with $5 \%$ total harmonic distortion.

- It mitigates the voltage swell from $10 \%$ to $0.5 \%$ and $7^{\text {th }}$ harmonic distortion is brought down from $31.2 \%$ to $7 \%$ at feeder 2 and regulates the load voltages with $7 \%$ total harmonic distortion.

- It mitigates the LLLG on feeder2 to normal values and regulates the load voltages in feeder with permissible THD limits

- It mitigates the sudden load changes in each feeder with permissible limits and mitigates all kind of power quality problems in multi feeder distribution systems with minimum real power injection.

The modelling of minimization of volt- ampere (VA) loading of MC-DVR is obtained by using the optimization techniques such as genetic algorithim and PSO. On comparison the best optimal injected angle for injection of voltage by GA is $26.89^{\circ}$ and by PSO is $20.68^{\circ}$ which is optimal. This reduces volt-ampere rating MC-DVR hence reduce cost.
Nomenclature
$v_{i}^{n+1} \mathrm{i}^{\text {th }}$ dimensions Velocity of particle at $(n+1)^{\text {th }}$ iteration
$x_{i}^{n} \quad$ Current position in the $\mathrm{i}^{\text {th }}$ dimension at $n^{\text {th }}$ iteration
$\mathrm{C}_{1} \quad$ Acceleration factor related to pbest
C2 Acceleration factor related to gbest
$T H D_{V_{-} L 1} \quad$ Total harmonic distortion in load voltages at feeder1
$\alpha \quad$ Voltage Injected angle
APF Active Power Filters 


\section{References}

Aleem S.H.E.A., Zobaa A.F., and Aziz M.M.A., 2012. Optimal $C$-type passive filter based on minimization of the voltage harmonic distortion for nonlinear loads" IEEE Transactions on Industrial Electronics, Vol. 59, No. 1, pp. 431-437.

Arnold R. 2001. Solutions to power quality problems, Power Engineering Journal, Vol. 15; No. 2, pp: 65-73.

Bollen M.H.J., 2003. What is power quality? Electric Power Systems Research, Vol. 66, No. 1, pp. 5-14.

Fujita H. and Akagi H., 1998. The unified power quality conditioner: The integration of series and shunt active filter," IEEE Transactions on Power Electronics, Vol. 13, no. 2, pp. 315-322.

Hamid R.M, Ali Y.V, and H. Mokhtari, 2009. Multiconverter unified power-quality conditioning systems, IEEE Transactions on Power Delivery, Vol. 24, No. 3, pp. 1679-1686.

Hague M. H. 2001. Compensation of distribution system voltage sag by DVR and D-STATCOM, IEEE Porto Power Tech Conference, Vol. $1,10^{\text {th }}-13^{\text {th }}$ Sept.

Aredes M., Heumann K., and Watanabe E. H., 1998. An universal active power line conditioner," IEEE Trans. Power Del. , Vol. 13, No. 2, pp. 545-551.

Jindal A.K., Ghosh A. and Joshi A., 2008. Voltage regulation in parallel distribution feeders using IVOLCON" Proceedings of IEEE.

Jindal A.K., Ghosh A. and Joshi A., 2007. Interline unified power quality conditioner, IEEE Transactions on Power Delivery, Vol. 22, No. 1, pp. 364-372.

Kesler, M., and E. Ozdemir 2011. Synchronous-reference-frame-based control method for UPQC under unbalanced and distorted load conditions, IEEE Transactions on Industrial Electronics, Vol.58,.No.9, pp.3967-3975.

Kinhal V.G., Agarwal P., and Gupta H.O. 2011. Performance investigation of neural-network-based unified power-quality conditioner. IEEE Transactions on Power Delivery, Vol. 26, No. 1, pp. 431-437.

Kolhatkar Y.Y. and Das S.P., 2007. Experimental investigation of a single-phase UPQC with minimum VA loading, IEEE Transactions on Power Delivery, Vol. 22, No. 1, pp. 373-380.

Panda. S, Padhy N.P. 2008. Comparison of particle swarm optimization and genetic algorithm for FACTS-based controller design", Applied Soft Computing Journal, Vol. 8, No. 4, pp. 1418-1427.

Reid W., 1996. Power quality issues-standards and guidelines, IEEE Transactions on Industry Applications, Vol. 32, no. 3, pp. 625-632.

Rodríguez P., Pou J., Bergas J., Candela J. I., Burgos R. P., and Boroyevich D., 2007. Decoupled double synchronous reference frame PLL for power converters control, IEEE Transactions on Power Electronics, Vol. 22, No. 2, pp. 584-592.

Saravanan M., Slochanal S.M.R., Venkatesh P., and Abraham J.P.S., 2007. "Application of particle swarm optimization technique for optimal location of FACTS devices considering cost of installation and system load ability," Electrical Power System Research, Vol. 77, pp. 276-283.

Sivakumar. G. 2012. "Minimisation of VA loading of UPQC in three-phase four-wire distribution system, International Journal of Power Electronics, Vol. 4, No. 2.

Wang B., Venkataramanan G., and Illindala M., 2006. Operation and control of a dynamic voltage restorer using transformer coupled H-bridge converters, IEEE Transactions on Power Electronics, Vol. 21, No. 4, pp. 1053-1061.

\section{Biographical notes}

Mr. Pudi Vasudeva Naidu was born in 1981. He obtained B.Tech (EEE) degree from Bapatla Engineering College, Nagarjuna University in India , M.Tech from JNTUCH in India and He is pursuing Doctrol Program at Nagarjuna University in India. Currenly he is an Assistant Professor at GITAM University. His areas of interest include Power electronics, Power Quality (PQ) and FACTS.

Dr. Banakara Basavaraja (M'04 -SM'10) was born in 1970. He obtained B.Tech (EEE) degree from Gulbaraga University in India, M.Tech from Karanatka University in India and Ph.D from National Insistitute of Technology Warangal. He is senior IEEE Member, Executive Member of ISTE and FIE member. Currently he is a Professor of Electrical \& Electronics Engineering Department at the University of BDT Engineering College Davanagere, (Visvesvaraya Technological University Belgaum) Karnataka. His areas of interest include Power Electronics, Adjustable Speed Drives (ASD), Power Quality (PQ), High voltage engineering and EMTP applications.

Received March 2014

Accepted April 2014

Final acceptance in revised form October 2014 